\title{
SENTIDOS DA JUDICIALIZAÇÃO DA POLÍTICA: DUAS ANÁLISES*
}

\author{
DÉBORA ALVES MACIEL \\ ANDREI KOERNER
}

A partir da transição política tem aumentado a presença de instituições judiciais, de seus procedimentos e de seus agentes na democracia brasileira. A sua visibilidade pública foi acompanhada pelo debate crescente de seu papel e pelo interesse de pesquisadores de ciências sociais pelo tema. Na ciência política, os estudos sobre as relações das instituições judiciais com as instituições políticas têm utilizado uma expressão que determina o enfoque e orienta o debate: a judicialização da política.

As duas obras aqui comentadas, Ministério Público e política no Brasil, de Rogério Bastos Arantes, e A democracia e os três poderes no Brasil, organizado por Luiz Werneck Vianna, dedicam-se ao assunto e oferecem, pois, a oportunidade de comparação das suas linhas interpretativas e de seus achados empíricos. Os dois livros são bastante diferentes na concepção, enfoque e escopo. Destacamos as apropriações dissonantes da idéia de judicialização da política, termo cujo uso se estende nesses anos.

Os livros resenhados têm grande diferença qualitativa em relação à maioria dos trabalhos que usam o termo. Seus conceitos de judicialização da política também são normativos, baseados em modelos conflitantes de República e com isso adotam diferentes abordagens do papel do Poder Judiciário na democracia brasileira. Ao final, questionamos a pertinência do uso do termo para a análise empírica das relações problemáticas entre instituições judiciais e instituições políticas na democracia brasileira.

\footnotetext{
* Comentário dos livros: Luís Werneck Vianna (org.). A democracia e os três poderes no Brasil. Belo Horizonte. Editora UFMG, 2002; Rogério Bastos Arantes. Ministério Público e política no Brasil. São Paulo. Editora Sumaré, 2002.
} 


\section{A JUDICIALIZAÇÃO E SEUS SIGNIFICADOS}

A expressão passou a compor o repertório da ciência social e do direito a partir do projeto de C. N. Tate e T. Vallinder (1996), em que foram formuladas de linhas de análise comuns para a pesquisa empírica comparada do Poder Judiciário em diferentes países. "Judicialização da política" e "politização da justiça" seriam expressões correlatas, que indicariam os efeitos da expansão do Poder Judiciário no processo decisório das democracias contemporâneas. ${ }^{1}$ Judicializar a política, segundo esse autores, é valer-se dos métodos típicos da decisão judicial na resolução de disputas e demandas nas arenas políticas em dois contextos. ${ }^{2} \mathrm{O}$ primeiro resultaria da ampliação das áreas de atuação dos tribunais pela via do poder de revisão judicial de ações legislativas e executivas, baseado na constitucionalização de direitos e dos mecanismos de checks and balances. $\mathrm{O}$ segundo contexto, mais difuso, seria constituído pela introdução ou expansão de staff judicial ou de procedimentos judiciais no Executivo (como nos casos de tribunais e/ou juízes administrativos) e no Legislativo (como é o caso das Comissões Parlamentares de Inquérito). ${ }^{3}$

Se na idéia da política judicializada estão em evidência modelos diferenciais de decisão, a noção de politização da justiça destaca os valores e preferências políticas dos atores judiciais como condição e efeito da expansão do poder das Cortes. A judicialização da política requer que operadores da lei prefiram participar da policy-making a deixá-la ao critério de políticos e administradores e, em sua dinâmica, ela própria implicaria papel político mais positivo da decisão judicial do que aquele envolvido em uma nãodecisão. Daí que a idéia de judicialização envolve tanto a dimensão procedimental quanto substantiva do exercício das funções judiciais.

A pretensão dos autores de dar estatuto conceitual à expressão "judicialização da política" foi questionada desde a publicação do livro (Reisinger, 1996). No Brasil, o termo passou a ser utilizado em pesquisas empíricas por Ariosto Teixeira (1997) e Marcus Faro de Castro (1997). Em

1 Tate e Vallinder, 1995

2 Os autores tipificam o comportamento decisório nas instâncias da justiça e da política. Na magistratura: 1 . presença de duas partes e um juiz; 2 . audição aberta e balanço dos argumentos; 3 . decisão de um juiz imparcial; 4. sentenças de casos individuais (conforme precedentes, especialmente nos casos de revisão judicial); 5 . verificação de fatos e de regra relevante (aplicada como a "única solução correta"). Na legislatura: 1 . presença de várias partes; 2 . barganhas e compromissos a portas fechadas; 3. princípio da maioria; 4. regras gerais, como as leis e orçamentos que orientam a policy making; 5. alocação de valores econômicos e políticos para a "solução política possível".

3 Essas duas formas de judicialização são denominadas, respectivamente, "from without" e "from within" 
suas análises de ações de insconstitucionalidade no STF eles já apontavam a inadequação do conceito, dado o pouco ativismo dos ministros. Werneck Vianna (1999) tomou o termo para descrever as transformações constitucionais pós-88, que permitiram o maior protagonismo dos tribunais em virtude da ampliação dos instrumentos de proteção judicial, e que teriam sido descobertas por minorias parlamentares, governos estaduais, associações civis e profissionais.

Mas a expressão ganhou o debate público e, com isso, multiplicaram-se os seus usos e sentidos, tornados às vezes contraditórios. De um modo geral, a expressão é utilizada em sentido normativo, tanto em relação ao papel atual dos agentes do sistema judicial, assim como em relação a propostas sobre a extensão adequada do seu papel na democracia brasileira. Segue-se um pequeno balanço dos sentidos emprestados ao termo, sem pretender de um levantamento exaustivo ${ }^{4}$.

Os juristas usam o termo judicialização para se referirem à obrigação legal de que um determinado tema seja apreciado judicialmente. Próximo a esse sentido, mas já com caráter normativo, afirma-se que judicialização é o ingresso em juízo de determinada causa, que indicaria certa preferência do autor por esse tipo de via. Refere-se a decisões particulares de tribunais, cujo conteúdo o analista consideraria político, ou referente a decisões privadas dos cidadãos (como questões de família). Decisões judiciais particulares poderiam ser sujeitas a escrutínio e seu conteúdo poderia ser avaliado como "grau de judicialização". A expressão é usada neste sentido mesmo para decisões que não são propriamente judiciais como no caso da verticalização das coligações políticas decidida pelo TSE. Ou refere-se à situação excepcional de maior número de conflitos políticos no Judiciário, própria aos períodos de eleições 5 .

A expressão recebe um sentido de processo social e político, quando é usada para se referir à expansão do âmbito qualitativo de atuação do sistema judicial, do caráter dos procedimentos de que dispõem e, ainda

\footnotetext{
${ }^{4}$ Fizemos uma pesquisa rápida na Internet, com a entrada "judicialização" no motor de busca "Google" do site Uol. Por brevidade, não apresentamos referência para todos os usos, só daqueles que nos pareceram mais significativos.

5 "Devido aos ataques atingindo o juiz de Barra Velha, Edson Luiz Oliveira, suspeito de favorecer a venda superfaturada de um terreno para a construção do novo prédio da Câmara de Vereadores, magistrados da Coordenadoria de Joinville decidiram defender o colega, enviando ofícios às Corregedorias de Justiça e Eleitoral. Entendem que os juízes devem receber o apoio desses organismos para que possam manter a serenidade e independência de atuação, principalmente em situações marcadas por tentativas de 'judicialização da política', comuns em ano eleitoral" (Diário Catarinense, 2/9/2002, p.8).
} 
aumento do número de processos nos tribunais 6 . A judicialização é tomada como um processo objetivo utilizado para defender propostas de mudança na organização do Judiciário ou na cultura jurídica, considerada defasada face às novas necessidades sociais ${ }^{7}$. Essa expansão pode ser interpretada em sentido sistêmico, em que a judicialização implicaria risco de perda das diferenciações funcionais entre os subsistemas do direito e da política (Campilongo, 2000). Embaralhados os subsistemas, seus agentes, modos de decisão e linguagens perderiam seu caráter próprio, o que indicaria uma tendência social crítica. Fala-se, ainda, de "judicialização do Estado" ou "judicialização do país" (Mello, 2001)

Em relação às causas do processo de judicialização, alguns atribuem-na à ação do legislador, constituinte ou ordinário, o governo federal, agentes políticos, grupos oposicionistas ou de associações (por exemplo, Faria, 1999). Há referências a macroprocessos de mudança social que teriam embaralhado as relações entre direito, política e sociedade. Outros concentram sua atenção no próprio Poder Judiciário (suas atribuições, as práticas e cultura de seus agentes) ou na legislação defasada (Reale, 2000). O termo aplica-se não só à ação dos juízes mas também os profissionais de outras carreiras judiciais (especialmente os membros do Ministério Público), que seriam os responsáveis pela judicialização da política, por utilizar "excessivamente" suas atribuições para levar os conflitos à justiça, ou para resolvê-los extra-judicialmente, tendo a lei e seu savoir-faire como referência. A expressão faz parte do repertório das ações de grupos políticos que defendem o recurso das arenas judiciais para ampliar a proteção estatal à efetividade de direitos de grupos discriminados ou excluídos ${ }^{8}$.

6 O fenômeno da judicialização das relações sociais está efetivamente ocorrendo e o direito tem realmente influído na vida social das pessoas. São vários os exemplos em que essa situação se verifica, como nos casos de mulheres que são agredidas pelos companheiros e crianças em situação de risco. Pôr evidente que o direito deve regular essas relações, até mesmo em defesa da dignidade da pessoa humana (Bacelar, 2002:2).

7 Para José R. Nalini, a "judicialização da política e a politização da Justiça são fenômeno universal, e o Brasil não escaparia dele. É comum o estranhamento recíproco nestes tempos de abertura de um novo trato relacional. Os prenúncios de intensificação desse contato dão a esperança de uma nova era de transparência. O Judiciário hermético de há dez anos deu lugar a uma instituição pró-ativa. Natural a reação dos interlocutores e mesmo a postura resistente dos magistrados mais conservadores". (Nalini, 2002)

8 "Neste século XXI, creio que o Estado, através de uma Constituinte Planetária, deverá revelar e consolidar os valores éticos e morais da nova sociedade informática, a começar pela própria América Latina. Revisando, assim, através de uma democracia direta (via Internet), a longa tradição secular e jurídica de dissimular a diversidade de comportamento sexual, de modo a fazer, abertamente, a judicialização da sexualidade humana. Espero que nos próximos dez anos, o Estado nacional venha a determinar, juridicamente, que a homossexualidade não é uma inversão ou doença, como julgam alguns párocos e educadores mais duros, mas uma opção sexual. Em substância, no século XXI em construção, a homossexualidade não será tabu” (Martins, 2002). 
No sentido constitucional, a judicialização refere-se ao novo estatuto dos direitos fundamentais e à superação do modelo da separação dos poderes do Estado, que levaria à ampliação dos poderes de intervenção dos tribunais na política. Se considerado um processo que põe em risco a democracia, a tendência seria agravada pelo nosso sistema híbrido de controle da constitucionalidade 9 .

É nesse controverso universo conceitual e normativo que vêm se inserir as análises divergentes de Rogério Arantes e de Luiz Werneck Vianna. Arantes utiliza a idéia de judicialização da política para referir-se ao ativismo voluntarista do Ministério Público e suas implicações negativas seja para a integridade das funções políticas das instituições representativas, ou ainda, para a própria manutenção da independência funcional da instituição. No volume organizado por Luis Werneck Vianna, convivem três dimensões do conceito que se reforçam mutuamente. Giselle Citadino retoma a dimensão constitucional das relações entre direito e política para identificar o espaço normativo aberto ao ativismo positivo de agentes sociais e judiciais na produção da cidadania; José Eisenberg avalia a expansão das práticas judicializadoras e a politização do Judiciário brasileiro como contrapeso a práticas conservadoras da classe política ou econômica. Werneck Vianna, por seu turno, reforça essas perspectivas ao tratar o fenômeno em termos de procedimentalização do direito e da ampliação dos instrumentos judiciais como mais uma arena pública a propiciar a formação da opinião e o acesso do cidadão à agenda das instituições políticas.

\section{MINISTÉRIO PÚBLICO E POLÍTICA NO BRASIL}

Concebido originalmente como tese acadêmica, o trabalho se insere na trajetória do pesquisador nos projetos desenvolvidos pelo IDESP sobre as instituições e os agentes do sistema de justiça no Brasil, com financiamento da Fundação Ford. Em realização há cerca de uma década, esses projetos deram origem a diversos livros e cadernos dedicados, principalmente, à investigação das orientações ideológicas, dos valores e dos

\footnotetext{
${ }^{9}$ Gilmar Ferreira Mendes faz este diagnóstico: "O modelo de convivência entre controle difuso e concentrado produziu, na democracia brasileira, o fenômeno da judicialização da política com contornos desconhecidos nas democracias maduras. Derrotadas nas arenas majoritárias, as minorias políticas procuram revogar na Justiça as decisões da maioria. A politização dos atores judiciais criou o ambiente atual, em que vigoram cerca de um milhão de liminares."
} 
diagnósticos dos agentes das diferentes organizações do sistema de justiça (juízes, promotores e, mais recentemente, delegados de polícia). Em suas linhas gerais, tais estudos têm adotado uma postura bastante crítica em relação à ampliação dos poderes do sistema judicial proporcionada pela Constituição Federal de 1988.

No seu conjunto, os trabalhos realizados pelo grupo apontam os aspectos negativos da combinação do controle concentrado da constitucionalidade com o difuso, que levaria a um híbrido institucional, com efeitos deletérios para a governabilidade (Arantes, 1997); também vêem como negativos os poderes de controle dos governantes do Ministério Público ampliados pela Constituição; criticam o uso que os promotores fazem da sua legitimidade ativa para propor ações civis públicas, sugerindo o substitucionismo da sociedade civil por parte da instituição, além de problemas de legitimidade da ampliação das fronteiras do sistema judicial sobre as instituições representativas. Os diagnósticos sobre a eficácia e acessibilidade do Judiciário brasileiro tendem a se concentrar na morosidade do Judiciário e seus efeitos negativos sobre a ineficiência econômica, dado que reduziria a segurança jurídica dos direitos de propriedade e levaria à diminuição dos investimentos privados no país (Arantes, 1996; Pinheiro, 1998, Lamounier, Pinheiro e Sadek, 2000) ${ }^{10}$. Ressaltam também os impactos indesejáveis da expansão do papel do sistema de Justiça no aumento de incerteza das decisões políticas. (Arantes, 1999)

O livro resenhado concentra-se na reconstrução institucional do Ministério Público a partir da transição democrática e sustenta-se em duas vertentes de análise, conforme apresenta o autor: uma institucional que aborda as mudanças legislativas e constitucionais das atribuições do Ministério Público (MP) na área dos interesses difusos e coletivos; a outra, substantiva, que investiga, por meio conceito de voluntarismo político, o universo ideológico de promotores e procuradores de justiça. A pesquisa empírica consistiu de survey e entrevistas em profundidade com membros do MP e pesquisa documental. O livro é composto de quatro capítulos nos quais o autor reconstrói o debate político e doutrinário no interior da instituição, analisa empiricamente a atuação do Ministério Público na área da improbidade administrativa (destacando o caso da máfia dos fiscais em São

10 Essa agenda de pesquisas assemelha-se à desenhada pelo Banco Mundial no início da década de noventa, cujos efeitos negativos têm sido criticados nos últimos anos (Garro, 1999; Sutil, 1999 ; Mendez, 1999). 
Paulo e as denúncias de corrupção de prefeitos e vereadores de cidades do interior) e, enfim, apresenta os dilemas da instituição no contexto da reforma do Judiciário.

A hipótese central que orienta a investigação é a de que as mudanças institucionais do Ministério Público, iniciadas na transição democrática, foram determinadas endogenamente pelas lideranças da instituição. Estas perseguiram intencional e sistematicamente a ampliação dos seus poderes, o que levou a instituição "a construir sua nova identidade institucional, conquistando independência e aproximando-se pretensiosamente da figura de quarto poder da República" (p. 22). Das reformas legislativas, continuamente propostas e/ou apoiadas por lobbies eficientes dos integrantes da instituição junto aos poderes Executivo e Legislativo, resultaram a conformação constitucional das novas atribuições e poderes.

Para demonstrar esta trajetória, Arantes sistematiza as mudanças legislativas das atribuições do Ministério na esfera cível, em curso a partir da década de 1970, argumentando que a instituição foi capaz de estabelecer uma linha de continuidade da sua legitimidade tradicional na proteção de incapazes e direitos individuais indisponíveis à sua legitimação na proteção dos direitos coletivos e difusos. O Código de Processo Civil de 1973 teria propiciado essa passagem ao atribuir ao Ministério Público a condição de órgão interveniente em causas em que houvesse interesse público, evidenciado "pela natureza da lide ou qualidade da parte" (art. 82 do CPC/1973). Nessa oportunidade, lideranças institucionais ampliaram o conteúdo doutrinário do conceito de interesse público, abrindo caminho para a transformação da instituição de agente do interesse estatal em representante dos interesses sociais. Mudanças legislativas ulteriores, como as Leis Orgânicas Federal, em 1981, e Estadual, em 1982, compatibilizaram essa reinterpretação com princípios de independência institucional e autonomia funcional.

O voluntarismo político, orientação ideológica dos membros do Ministério Público brasileiro na busca da afirmação do papel politizado da instituição, seria constituído pela visão de uma sociedade civil incapaz de defender seus interesses e de instituições políticas insatisfatórias no cumprimento do seu papel representativo. Central para tal interpretação é a alegada concepção de promotores e procuradores de que a sociedade brasileira seria "hipossuficiente", identificada pelo survey realizado com membros do Ministério Público, em estudo IDESP de 1994. Neste, 84\% dos entrevistados concordaram total ou parcialmente com a afirmação de que "a sociedade brasileira é hipossuficiente, isto é, incapaz de defender 
autonomamente os seus interesses e direitos, e que por isso as instituições da justiça devem atuar afirmativamente para protegê-la". A mesma proporção atribuiu ao MP o papel de promotor da conscientização e de responsabilização da sociedade brasileira com vistas ao alargamento do acesso à Justiça das demandas sociais, em especial as de natureza coletiva. Esses resultados seriam indicadores de uma visão tutelar da sociedade brasileira, na qual o desenvolvimento da cidadania dar-se-ia não pela via de instituições representativas, mas por meio de um poder externo, preferencialmente a-político. (pp. 16 e 129-130). Arantes traça, pois, o paralelo entre o universo dos valores ideológicos do MP e as concepções elitistas de organização da sociedade pelo alto e, em particular, o autoritarismo instrumental de Oliveira Vianna.

Arantes identifica o caráter verticalizado e paternalista do novo papel da instituição no perfil de intervenção nos conflitos sociais e políticos, praticado pelo MP. Na análise da autoria das ações civis públicas, ele interpreta o elevado número de ações iniciadas pelo MP, em comparação com as das associações civis, como efeito dos constrangimentos e benefícios distribuídos pela Lei da Ação Civil Pública, de 1985, que "só reconheceu os setores previamente organizados e, quanto aos não-organizados, ela sinalizou que o caminho mais racional e eficiente seria bater às portas do Ministério Público" (id., p.71). Assim, em contraposição ao senso comum "de que a grande defasagem existente entre o número de ações civis públicas patrocinadas pelas associações civis e pelo MP decorreria de razões sócio-políticas", os novos instrumentos legais teriam reforçado "extraordinariamente" os recursos organizacionais e processuais da instituição frente aos da sociedade civil, eternizando o "princípio tutelar que sempre orientou a relação entre Estado e sociedade no Brasil" (id., p. 75-6).

Por fim, o autor analisa os dilemas do Ministério Público brasileiro face à reforma do Judiciário. As mudanças propostas são analisadas como ameaças à independência judicial da instituição e interpretadas como reações da política ao fáustico projeto institucional das lideranças internas. Em síntese, o voluntarismo político orientador da reconstrução institucional teria resultado na ampliação desmesurada da intervenção do sistema judicial nos conflitos políticos e na constituição de um modelo institucional contraditório que politizou um órgão de justiça independente, tornando-o um "agente político da lei." Esse ativismo judicial do MP expressaria a face politizada da justiça, contrapartida da judicialização da política.

Não obstante o mérito do trabalho de Arantes na identificação das mudanças legislativas que, mesmo antes de 1988, foram redesenhando 
o papel do MP no sistema de justiça, o enfoque analítico adotado é problemático. Embora o próprio autor reconheça os riscos da explicação ex post facto centrada na intencionalidade dos atores (p. 23, nota 6), os limites dessa escolha tornam-se ainda maiores em virtude da pretensão generalizante do modelo explicativo. Processos de mudança institucional resultam das interações entre os diversos agentes internos e externos e isso, a nosso ver, requereria o cuidado na distinção dos níveis de generalidade analítica, dos mais amplos (nomeadamente, o contexto político e institucional da transição democrática) aos mais restritos, o dos eventos a serem reconstituídos (o processo de mudança legislativa e as intenções dos agentes internos). Essa atenção metodológica permitiria à investigação, de fato, lançar luz sobre uma das dimensões da trajetória recente do Ministério Público brasileiro, controlando a tentação de explicar o sucesso da reconstrução institucional pela ótica exclusiva da capacidade estratégica de agentes isolados de adequarem meios a fins.

Essas premissas metodológicas orientam interpretações discutíveis tanto da retórica institucional como dos padrões de interação do Ministério Público com o ambiente externo, em particular com as organizações sociais. Uma primeira interpretação controversa é relativa às afirmações dos membros do MP quanto a hipossuficiência da sociedade civil, tomadas por Arantes como sinal inequívoco da concepção tutelar (logo, autoritária e paternalista) da instituição. Os conceitos de hipossuficiência, assim como o de tutela, têm dimensão jurídica - é provável que os integrantes do MP os tenham interpretado nesse sentido em suas respostas - e, por isso, parece-nos no mínimo apressado dar-lhes um conteúdo políticoideológico imediato. $\mathrm{O}$ mesmo ocorre com as concepções de promotores e procuradores do seu papel pedagógico e ativo na promoção dos direitos coletivos. Tais afirmações constituem não matéria de opinião mas remetem ao próprio desenho institucional do MP e à função profissional dos seus membros. Trata-se de atribuições e objetivos da organização que, legitimados pela Constituição e reafirmados em diversos diplomas legais, mais traduzem o significado atribuído às instituições judiciais nas democracias contemporâneas do que expressam ideologias estritamente corporativas dos seus membros.

Dessa ótica, caberia perguntar se as organizações de justiça seriam, de fato, tão impermeáveis e autônomas em relação às expectativas, interesses e orientações morais, presentes no ambiente sociocultural mais amplo. Conforme tivemos oportunidade de mostrar em pesquisa sobre a atuação do Ministério Público em conflitos ambientais (Maciel, 2002), o 
movimento ambientalista emergente no contexto da transição democrática encontrou em lideranças institucionais fortes aliadas para a inserção das suas demandas na agenda política brasileira. A permeabilidade e abertura da instituição a valores do ambiente externo acabaram por conferir-lhe crescente visibilidade pública e legitimação social à sua intervenção nas disputas de natureza coletiva e difusa. ${ }^{11}$

A segunda objeção interpretativa refere-se ao perfil de ação do Ministério Público e de grupos sociais, traçado por Arantes com base nos dados das ações civis públicas. $\mathrm{O}$ binômio explicativo instrumentalismo associativo / substitucionismo institucional deixa escapar, por um lado, as múltiplas motivações dos agentes sociais no encaminhamento de demandas ao sistema de Justiça em função dos dilemas organizacionais próprios da ação coletiva ou das escolhas deliberadas de arenas alternativas de acordo com os seus graus de permeabilidade às expectativas dos atores em conflito. Esses aspectos ilustram diversos estudos tanto da dinâmica de acesso à Justiça como das orientações de conduta (valorativas e práticas) dos movimentos e associações coletivas. Por outro lado, a hipótese do substitucionismo desconsidera o papel legitimador das denúncias e representações que, em quantidade significativa, têm sido oferecidas por agentes socais, políticos e estatais ao Ministério Público, segundo indica o perfil desenhado pelo trabalho de Werneck Vianna, apresentado a seguir.

\section{A DEMOCRACIA E OS TRÊS PODERES NO BRASIL}

O volume organizado por Luís Werneck Vianna é obra coletiva, elaborada a partir da criação de instituto de pesquisa (o Instituto Virtual "A Democracia e os Três Poderes no Brasil", convênio IUPERJ-FAPERJ) e reúne trabalhos de pesquisadores de diferentes instituições do Rio de Janeiro. O tema é tratado sob dois eixos de análise, a relação "horizontal" entre os poderes do Estado e destes com a sociedade civil. A hipótese central que orienta os trabalhos é a de que não obstante o processo de consolidação institucional da democracia brasileira, ela experimentaria um déficit no modo do seu funcionamento, resultante da predominância do Executivo sobre o Legislativo e do insulamento da esfera parlamentar em relação à sociedade civil. Contudo, observar-se-ia também reações da

11 Os membros do Ministério Público paulista, por exemplo, são mais divididos em relação ao seu papel profissional e político do que supõe a tese do autor. Ver Silva, 2001. 
cidadania ao fechamento desses poderes às suas demandas e expectativas, indicadas pela busca crescente do Poder Judiciário contra leis, práticas da Administração ou omissões tanto do Executivo quanto do Legislativo (Vianna, 2002: 8-10).

Assim, o escopo da obra é amplo, compondo-se de ensaios teóricos e trabalhos empíricos e, conforme adverte o organizador, as interpretações são diversificadas e apresentam as dissonâncias típicas desse tipo de empreendimentos intelectual. Os ensaios teóricos giram em torno dos temas da teoria constitucional e da judicialização da política (Gisele Cittadino, José Eisenberg, Manuel Palacios Cunha Melo). Os artigos empíricos tratam de três conjuntos de temas: as relações entre o Executivo e o Legislativo, com trabalhos sobre o processo legislativo, as atribuições legislativas do Poder Executivo na história constitucional brasileira e o processo decisório das agências regulatórias (respectivamente, Octavio Amorim Neto e Fabiano Santos, Charles Pessanha, Renato Raul Boschi e Maria Regina Soares de Lima); a participação eleitoral e a cultura cívica (Jairo Nicolau, Maria Alice Rezende de Carvalho); e o volume conclui com a pesquisa de Luiz Werneck Vianna e Marcelo Burgos sobre o perfil dos conflitos encaminhados às instituições judiciais por meio de ações coletivas (ação popular e ação civil pública) e o estudo de Adalberto Moreira Cardoso sobre a evolução de demandas individuais ao judiciário trabalhista. Neste último aspecto, o livro dá continuidade às pesquisas coordenadas por Werneck Vianna sobre o perfil dos magistrados e o papel das instituições do sistema judicial pós-1988 (Vianna et allii, 1997 e 1999)

O livro abrange um amplo conjunto de temas, cujo tratamento completo ultrapassaria os limites desta resenha. Destacamos que a abordagem das relações entre os poderes do estado e destes com a sociedade civil oferece perspectiva ampliada de análise das interseções entre política e justiça. Ademais, mais do que a mera aplicação do modelo empíricoanalítico de Tate e Vallinder, ensaios teóricos enfrentam as dimensões normativas do problema, identificando os pressupostos das posições no debate, como é o caso, por exemplo, dos artigos de Giselle Cittadino e de Luís Werneck Vianna e Marcelo Burgos.

Gisele Cittadino discute as bases éticas e jurídico-normativas do constitucionalismo democrático, dando continuidade a seu trabalho anterior (Cittadino, 2000). Ao contrário do constitucionalismo liberal, que seria marcado pela defesa do individualismo racional, a garantia limitada dos direitos civis e políticos e clara separação dos poderes, o constitucionalismo democrático priorizaria os valores da dignidade humana e da soli- 
dariedade social, a ampliação do âmbito de proteção dos direitos e a redefinição das relações entre os poderes do Estado. Para esta concepção, abrir-se-ia no Judiciário um novo espaço público, no qual participam novos agentes (a comunidade de intérpretes), os quais, segundo procedimentos determinados, dedicar-se-iam à interpretação aberta dos valores compartilhados pela comunidade com vistas a sua efetivação.

A Constituição de 1988 teria sido marcada pela ação de juristas adeptos dessa linha de pensamento e teria incorporado os seus conceitos fundamentais, deslocando a cultura jurídica predominante até então, marcada pelo positivismo de caráter privatista. Disso resulta a ampliação da concepção dos direitos fundamentais, não mais considerados normas programáticas que dependem da vontade do legislador, mas afirmações de princípios que constituem programas de ação, objetivos que implicam o dever de ação do Estado. A efetivação dos direitos fundamentais seria obra do círculo de intérpretes na esfera judicial construída por meio de instrumentos processuais-procedimentais. Nessa perspectiva, a judicialização da política seria o "processo por meio do qual uma comunidade de intérpretes, pela via de um amplo processo hermenêutico, procura dar densidade e corporificação aos princípios abstratamente configurados na Constituição" (p. 39). Tal fenômeno expressaria, portanto, o processo, resultante da transformação constitucional e seu efeito (a expansão do âmbito de atuação do Judiciário), o qual não seria contrário à política democrática, mas estaria em consonância com ela.

Werneck Vianna e Marcelo Burgos reiteram a análise do significado da transformação constitucional de 1988, apresentada em livro anterior, A judicialização da política e das relações sociais no Brasil, introduzindo, porém, duas novidades teóricas: a aproximação da ampliação do direito com o conceito de americanismo e a redefinição do tema da judicialização em termos de revolução procedimental ou procedimentalização do direito. Em extensa apresentação do capítulo, os autores utilizam-se do conceito gramsciano de americanismo deslocando-o do mundo fabril para o âmbito da sociedade civil e do mundo da vida, em clara adesão ao universo analítico habermasiano. As formas de vida do homem comum seriam, potencialmente, criadoras de uma eticidade não contraposta ao Estado mas seu pressuposto e extensão, necessária para o não insulamento do direito estatal na formalização burocrática e no ritualismo processual (pp. 354-5). Com base na discussão de Habermas da procedimentalização do direito, os autores interpretam que as transformações contemporâneas do direito o teriam tornado aberto às aspirações e necessidades coletivas 
sem, contudo, atrelá-lo ao conjunto de imperativos morais substantivos de uma comunidade ética fechada. A institucionalização do direito no mundo contemporâneo teria incorporado princípios da filosofia política da modernidade, transformando-os em formas de ação à disposição do homem comum para participar da criação do direito estatal tanto através da democracia representativa como pela via judicial. Essa participação não seria fragmentadora daqueles princípios da vontade geral mas representaria as possibilidades de adensamento do direito pela intervenção, na esfera estatal, da eticidade da sociedade civil. (pp. 358-9).

A revolução procedimental teria ampliado os espaços para o exercício de uma "soberania complexa", que consistiria na combinação de duas formas de representação, a política e a funcional, e de duas dimensões da cidadania, a política e a social; a primeira exercida pelos representantes eleitos com base nos procedimentos democráticos e a segunda, pela comunidade de intérpretes, composta inclusive pelos agentes judiciais legitimados pela Constituição. Assim, "(...) se a cidadania política dá as condições ao homem comum de participar dos procedimentos democráticos que levam à produção da lei, a cidadania social lhe dá acesso á procedimentalização na aplicação da lei por meio de múltiplas formas, individuais ou coletivas, de um simples requerimento a uma ação pública, proporcionando uma outra forma de participação na vida pública" (p. 372). A representação funcional permitiria, pois, o acesso do cidadão à aplicação/efetivação do direito, criando um direito "responsivo", aberto aos interesses e concepções éticas do homem comum, mas capaz de manter a integridade de seus princípios.

Esses pressupostos guiam a formulação da pesquisa empírica do acesso à justiça de demandas sociais pela via das chamadas class actions, as ações coletivas. Os autores pesquisaram as ações populares e as ações civis públicas em tramitação no Fórum central da cidade do Rio de Janeiro identificando os autores, os réus e os objetos reclamados. Constam também do retrato traçado dados relativos aos resultados das ações judiciais que, colhidos de ações em curso, conforme reconhecem os autores, não permitem mais do que hipóteses muito parciais e provisórias acerca das respostas dadas pelos agentes do sistema de justiça às demandas e conflitos sociais e políticos. Do conjunto de dados apresentados, merecem destaque alguns achados empíricos relativos às ações civis públicas e ao perfil da interação entre agentes sociais e políticos e o Ministério Público.

Quanto aos autores, a pesquisa indica a significativa participação de associações civis e políticas, órgãos estatais e cidadãos no ofe- 
recimento de denúncias ao MP. Na proposição de ações civis, há indícios de crescimento daquelas de autoria das associações civis na segunda metade da década de noventa em comparação com o decênio anterior. Ademais, ainda que, de fato, sejam destacadas as iniciativas judiciais dos membros do Ministério Público, a participação das associações civis tende a crescer em virtude dos recursos organizacionais disponíveis, como parece indicar a freqüência de ações propostas na área do consumidor.

A participação de órgãos estatais como autores de ações coletivas mostra a face cooperativa das relações estabelecidas entre administradores e promotores de justiça. Os órgãos públicos muitas vezes dirigem-se ao MP para acionar outros órgãos públicos (na Promotoria de Cidadania este é o caso de mais da metade das ações civis públicas). Este perfil dos autores também foi encontrado em nossa própria pesquisa empírica sobre a atuação do MP em conflitos ambientais no Estado de SP (Maciel, 2002). Isso reforça a hipótese de que o MP tem desempenhado o papel de coordenação e mediação entre as diversas agências estatais, valendo-se de maneira significativa de instrumentos extrajudiciais na resolução de disputas.

Esses resultados colocam em questão a tese do substitucionismo da sociedade civil operado pelo MP, defendida por Arantes. Os autores rejeitam também as críticas de que o MP estaria substituindo o Poder Judiciário, ao usar seus poderes extrajudiciais para resolver conflitos coletivos. Para os autores, a ação do MP faz como parte da constituição de um complexo sistema de complementaridade e interdependência entre os poderes do Estado, a mídia, a cidadania organizada e os indivíduos. Assim, “(...) mais do que transferência, prevalece o compartilhamento de responsabilidades entre os diferentes atores envolvidos...". A solução dos conflitos coletivos tem demandado "a construção de redes institucionais que abarcam, além do MP e entidades sociais, o próprio poder público”. O MP não substituiria o Judiciário, mas funcionaria muitas vezes "como uma instância que agrega esforços, visando construir uma base institucional para o cumprimento do direito". O MP atuaria preventivamente, "o que lhe confere um papel complementar e não concorrente em relação ao Poder Judiciário" (id., p. 444). O MP teria também o papel de superar problemas de coordenação entre esferas da administração pública.

Os objetos das ações são tanto aqueles tradicionais de defesa da moralidade pública, de busca de proteção do cidadão contra violações de seus direitos causadas por omissões do Estado, como também ações propositivas, que visam provocar a adoção de políticas públicas pelas 
autoridades governamentais. Embora em proporção ainda limitada, essas ações por políticas públicas estariam crescendo, o que revelaria maior protagonismo dos cidadãos para influenciar, pela via judicial, a formulação da agenda pública. No que se refere aos réus, não são apenas órgãos públicos os acionados pelas ações, mas também empresas, associações civis e cidadãos, o que depende diretamente do objeto das mesmas. Isso tem como conseqüência algumas reservas em relação à tese de Arantes de que os agentes políticos seriam os alvos preferenciais do MP nas ações coletivas.

Aparece aqui a figura do MP mais como um agente de mediação entre agentes sociais e poderes políticos do que um agente de judicialização, que provoca a intervenção de um poder externo e supostamente despolitizado a fim de solucionar de forma tutelar os conflitos. Poder-se-ia considerá-lo um mediador institucionalizado que dispõe de legitimidade jurídica e recursos organizacionais para a proposição de ações judiciais. Mas esta não é sua característica específica, pois outros agentes (fiscais) do Executivo podem fazê-lo. Em comparação com estes, o MP dispõe de menos recursos, pois não tem meios imediatos e efetivos de ação para obter a aquiescência e punir aqueles aos quais visa a sua ação (como poder de determinar ações emitir multas e fechar estabelecimentos).

Com relação às decisões judiciais, os autores advertem que os seus resultados são muito parciais pois se referem a ações ainda em curso. Porém, eles apontam algumas tendências presentes tanto no julgamento das ações populares como das ações civis públicas, que é o maior acolhimento, pelo Judiciário, de demandas relativas aos "novos direitos" difusos e coletivos e que envolvem políticas públicas, e a maior resistência judicial a temas "antigos" como o controle da moralidade administrativa e das práticas políticas. Embora os autores não explorem o tema, parece-nos que é uma nova indicação da resistência, ao menos parcial, dos juízes (aqui os de $1^{\mathrm{a}}$ instância), em assumir as demandas de maior ativismo, apresentadas por diferentes atores políticos e sociais, que já foi apontada em outros estudos empíricos sobre o Judiciário (Vianna, 1999; Castro, 1997). Como se sabe, o ativismo judicial é uma dimensão essencial da noção de judicialização da política formulado por Tate e Vallinder.

A interpretação proposta é instigante, pois amplia a discussão das relações entre instituições judiciais e política para as relações do Estado com a sociedade civil. Os autores substituem o conceito de judicialização da política pelo de procedimentalização do direito, que torna mais específica à definição da mudança que analisam. Como vimos a procedimentalização diz respeito às formas de ação judicial e ao conteúdo da ética do homem 
comum. A ampliação da análise do direito envolve seus vínculos com a dimensão da eticidade da sociedade civil e, pois, do exercício da cidadania. Os autores deslocam-se, pois, da arquitetura liberal que opõe Estado e sociedade civil e considera os procedimentos judiciais como uma parcela do exercício do poder, que se exerce por um dos poderes do Estado em prol de um indivíduo, mas necessariamente contra outros (indivíduos e poderes do Estado). Enfim, o trabalho tem um forte aspecto prospectivo no que se refere aos caminhos e potencialidades da ampliação da efetividade dos direitos fundamentais nas democracias, a brasileira em especial.

Contudo, com o deslocamento do foco de análise parece-nos pouco adequado o tratamento dado à dinâmica institucional na qual estão inseridas as organizações judiciais.

A passagem da macro-interpretação da procedimentalização no mundo contemporâneo para o caso brasileiro não considera suficientemente os efeitos do padrão histórico de mudança política sobre as instituições e práticas institucionais, bem como os seus efeitos sobre a procedimentalização do direito entre nós. Esse tema é sugerido pelo trabalho de Boschi e Lima, no volume, que afirmam a necessidade de considerar as inovações institucionais em relação aos formatos, agentes e práticas existentes num determinado contexto social. De que maneira a procedimentalização - no sentido restrito das ações coletivas - estaria sendo reinterpretada segundo as práticas da cultura jurídica dominante, marcada pelo positivismo privatista, e pelos interesses particulares dos profissionais das instituições judiciais? Assim torna-se relevante considerar as dissonâncias e não apenas a sinergia entre a interpretação das ações coletivas e dos princípios fundamentais dada pelos profissionais ao direito e a da eticidade do homem comum.

Estudos empíricos e relatos de agentes daquelas instituições têm mostrado as fortes tensões e a competição entre elas ${ }^{12}$. As instituições também sofrem fortes tensões internas, em que se formaram grupos internos polarizados com projetos e interesses contraditórios, cujas disputas pelo controle dos rumos das instituições se tornaram bastante acirradas. Essas instituições são, ainda, bastante criticadas por associações civis e agentes políticos, dado que não respondem ás expectativas pela ativa atuação no sentido da efetividade dos direitos. Os críticos apontam a forte presença da cultura positivista e privatista entre os agentes judiciais, com o que eles

12 Por exemplo, nos survey do IDESP profissionais de uma das carreiras judiciais atribuem aos de outra a culpa pelos problemas de funcionamento do Judiciário. 
"traduzem" muitas vezes os complexos conflitos coletivos na linguagem, procedimentos e rituais adequados a litígios interindividuais cuja resolução poderia ser alcançada pela decisão judicial sobre um caso particular ${ }^{13}$.

Assim, pensamos que o retrato sobretudo otimista da atuação das instituições do sistema judicial nas ações coletivas deve ser relativizado. É preciso desenvolver pesquisas empíricas que enfoquem as dimensões intra e inter-institucionais assim como a relação entre o conteúdo das decisões e as expectativas dos sujeitos, a fim de que se possa ter uma visão mais adequada da relação entre o sistema de justiça e a eticidade do mundo da vida. Esta mesma sujeita a fortes tensões, dadas as violências a que são submetidos cidadãos e comunidades no seu cotidiano.

Enfim, a pesquisa empírica de Werneck Vianna torna flagrante a diluição da própria idéia de judicialização da política na medida em que o autor indica a convivência, ao mesmo tempo, conflituosa e cooperativa entre as instâncias políticas e judiciais; ou, ainda, na medida em que afirma que "o Ministério Público tem evitado judicializar esses conflitos [os da Promotoria da Cidadania], preferindo direcionar esforços para a construção de acordos políticos na arena dos inquéritos civis." (id., p. 446). Deste modo, não considera mais a intervenção do MP em conflitos como indicadora, por si só, da judicialização. Fica, pois, a impressão de que quanto mais contextualizado o foco analítico, menos consistente e vantajoso parece ser o recurso ao conceito de judicialização para identificar a dinâmica da expansão das fronteiras do sistema judicial e os seus efeitos institucionais.

\section{CONCLUSÃO}

A concepção original de judicialização da política é marcada por uma concepção formal das atribuições e relações os poderes, assim como uma conotação de progressividade, de processo unidirecional cuja pertinência empírica é discutível. No Brasil, o debate público incorporou a expressão num sentido fortemente normativo e provocou a proliferação dos seus sentidos. A produção acadêmica também apresenta fluidez no uso da expressão, a qual não se torna mais do que um nome que é tomado como ponto de partida para análises cujas perspectivas são bastante divergentes.

13 Procuramos explorar esses aspectos em nossos trabalhos (Koerner, 2002a; 2002b) 
O deslocamento do debate para o campo do Ministério Público não trouxe maior precisão à questão, antes o que se vê é a insuficiência dos dados sobre o ativismo dos promotores e a divergência sobre a sua atuação em face aos demais agentes sociais e políticos.

No cerne das divergências entre os livros resenhados estão dois modelos de constituição e de república, que orientam a problemática e o desenho das suas pesquisas. Na abordagem de Arantes, o modelo de uma república constitucional com marcada separação dos poderes, cujo equilíbrio mantém o predomínio das instâncias eleitorais-majoritárias de representação. O modelo da Constituição é o liberal e o do Judiciário, de órgãos técnicos voltados predominantemente à aplicação da lei aos casos individuais e com limitada interferência nas decisões legislativas e governamentais.

Werneck Vianna toma como modelo uma república constitucional, em que há cooperação e complementaridade entre os poderes na produção de decisões políticas, para as quais concorrem formas de representação eleitorais e funcionais. As dimensões da participação política e a deliberação pública são enfatizadas. O modelo da Constituição é o democrático-comunitário, no qual o Judiciário tem o papel de formular, segundo determinados procedimentos de que participa a comunidade de intérpretes, os valores compartilhados, bem como o de servir de canal de expressão para grupos que demandem a promoção dos objetivos comuns expressos pelos direitos fundamentais. Assim, amplia-se o escopo, a visibilidade e as ocasiões em que os seus agentes atuam em relação às autoridades governamentais, à burocracia e outros espaços sociais.

As obras de teoria política incorporadas pela discussão apresentada nessa resenha adotam formulações de teoria do direito e de direito constitucional para a análise do sistema judicial nas democracias contemporâneas, tratando-o a partir de conceitos referentes à Constituição e à divisão de poderes do Estado. Essas formulações são combinadas com análises macro-sociológicas sobre transformações sociais das últimas décadas. Esse ângulo de interpretação é suficiente para estudos jurídicoconstitucionais sobre a dinâmica dos poderes políticos e é útil como quadro geral. Neste sentido, a contribuição de Citadino mostra que o modelo de república adotado por Arantes é inadequado para a análise daquela dinâmica no Brasil pós-1988.

Embora possam constituir um ponto de partida útil, essas formulações não nos parecem constituir base suficiente para a formulação de problemas de pesquisa empírica sobre as instituições judiciais. Em especial, é preciso tratar o tema das relações entre judiciário e política na 
democracia brasileira sem o recurso ao conceito pouco preciso, mas de rápida circulação pública, de judicialização da política.

Há, pois, espaço para conceitos mais específicos para a elaboração de problemas de pesquisa. No plano macro-institucional, seria o caso de avaliar o papel das instituições judiciais no conjunto de transformações do Estado brasileiro, nas duas últimas décadas, centrando a atenção no path histórico desse conjunto, assim como na dinâmica organizacional das diversas burocracias que compõem o sistema judicial. É essencial considerar a crise do Estado desenvolvimentista e seu complexo corporativo de representação de interesses, além das tensões entre o modelo da Constituição de 1988 e o das reformas constitucionais posteriores, cujo sentido foi o de mudar o marco das relações entre os poderes e destes com a sociedade. No plano social, as transformações poderiam ser abordadas de uma perspectiva construtivista, atenta para as formas de normatividade social elaboradas por atores coletivos.

Define-se assim um plano mais complexo de interações entre os agentes sociais, políticos e judiciais nas diferentes arenas de decisão. O padrão de decisões judiciais seria referido a esse plano, a partir do qual podem-se formular pesquisas empíricas sobre o comportamento decisório em relação a temas e objetos específicos, evidenciando-se, assim, os impactos daquelas transformações sobre a prática judicial, bem como os projetos alternativos de juristas e operadores do direito às situações de mudança e de recalcitrância.

Dado o nosso ainda precário conhecimento empírico sobre as instituições e práticas judiciais brasileiras, é preciso uma massa de pesquisas e de análises mais sistemáticas para elaborar diagnósticos generalizantes sobre o seu papel na dinâmica democrática brasileira.

DÉBORA ALVES MACIEL é professora da PUC-SP e membro do IEDIS.

ANDREI KOERNER é pesquisador do Núcleo de Estudos da Violência da USP - Programa CEPID/FAPESP e coordenador do IEDIS. 


\section{REFERÊNCIAS BIBLIOGRÁFICAS}

ARANTES, Rogério. 1996. "A crise do Judiciário no Brasil". Trevisan, n.o 104, pp. 18-27

ARANTES, Rogério Bastos. 1997. Judiciário e Política no Brasil. São Paulo. Editora Sumaré/FAPESP/EDUC.

ARANTES, Rogério Bastos. 1999. "Judiciário e democracia no Brasil". Novos Estudos Cebrap, n.o 54.

BACELLAR, Roberto Portugal. 2002. "O poder paralelo e o Judiciário. Quando a Justiça falha, a violência não tarda". Novos Rumos. Órgão Oficial da Associação dos Magistrados do Paraná, n.o 76, p. 2.

CAMPILONGO, Celso Fernandes. 2000. "Governo representativo versus governo dos juízes: a autopoiese dos sistemas político e jurídico". Revista de Direito Constitucional e Internacional, ano $8, \mathrm{n}^{\circ} 30$.

CASTRO, Marcus Faro de. 1997. "O Supremo Tribunal Federal e a judicialização da política". Revista Brasileira de Ciências Sociais, vol. 12, n.o 34.

CITTADINO, Gisele. 2000. Pluralismo, direito e justiça distributiva. Elementos da filosofia constitucional contemporânea. Rio de Janeiro. Lumen Juris.

FARIA, José Eduardo. 1999. "O Supremo e a judicialização da política”. O Estado de São Paulo, 6/11/1999.

GARRO, Alejandro. 1999. "Access to Justice for the Poor in Latin America". em O’Donnell, G. e Pinheiro, P.S. The (Un)Rule of Law \& the Underprivileged in Latin America. Notre Dame University Press, pp. 278-301.

KOERNER, Andrei. 2002a. Judiciário, juizes e prisões em São Paulo nos anos noventa. Anuário Direito e Globalização, 2003/1 : "Impactos da globalização. Ordem jurídica do Mercosul. Controle. Justiça. Direitos fundamentais". Atas do Seminário do GEDIM. Rio de Janeiro. Editora Lumen Juris.

. 2002b. "Justiça consensual e conflitos de família: algumas reflexões". em Agostinho, Marcelo e Sanchez, T. (org.) Família: conflitos, reflexões e intervenções. São Paulo. Editora Casa do Psicólogo.

2002c. "Posições doutrinárias sobre o direito de família no Brasil pós-1988. Uma análise política". em Fukui, Lia (org.) Segredos de Família, publicação do NEMGE/USP - Núcleo de Estudos sobre a Mulher e as Relações de Gênero. Editora Anablume/FAPESP.

MACIEL, Débora Alves. 2002. Ministério Público e sociedade: a gestão dos conflitos ambientais em São Paulo. Tese de doutorado em Sociologia. FFLCH, USP.

MARTINS, Vicente. 2002. "Por que excluir os gays nas escolas?". Grupo Gay da Bahia GGB. Documento extraído da Internet.

MELO, André Luís Alves de. 2001. "A judicialização do Estado brasileiro, um caminho antidemocrático e monopolista”. Teresina. Jus Navigandi, a. 6, n.o 52, nov. 2001. Disponível em: http://www1.jus.com.br/doutrina/texto.asp?id=2408>.

MÉNDEZ, Juan. 1999. "Institutional Reform, Inclunding Acess to Justice: Introduction", em O’Donnell, G. e Pinheiro, P.S. The (Un)Rule of Law \& the Underprivileged in Latin America. Notre Dame University Press, pp. 221-227

NALINI, José R. 2002. "Com as próprias pernas". O Estado de São Paulo, 21/01/02, p. A2

PINHEIRO, Armando Castelar. 1998. "A reforma do Judiciário: uma análise econômica". Apresentado no Seminário Internacional "Sociedade e Reforma do Estado", São Paulo, 26 a 28 de março de 1998.

REALE, Miguel. 2000. "Um brasileiro do século". Entrevista ao Jornal da Tarde, 04/11/2000.

REISINGER, William M. 1996. Resenha de The Global Expansion. Law and Politics Book Review, vol. 6, $\mathrm{n}^{\circ} 1$.

SILVA, Cátia Aída. 2001. Justiça em jogo. Novas facetas da atuação dos promotores de 
justiça. São Paulo. EDUSP. Série Biblioteca Edusp de Direito.

SUTIL, Jorge C. 1999. "Judicial Reform in Latin America: Good News for the Underprivilegied?". Em The (Un)Rule of Law \& the Underprivileged in Latin America, citado, pp. 255-77.

TATE, C. Neal e VALLINDER, Torbjorn. 1995. The Global Expansion of Judicial Power. New York University Press, 1995

TEIXEIRA, Ariosto. 1997. A judicialização da política no Brasil (1990-1996). Dissertação de Mestrado, Brasília, UnB.

VIANNA, Luís Werneck et allii. 1999. A judicialização da política e das relações sociais no Brasil. Rio de Janeiro. Editora Revan.

VIANNA, Luís Werneck et allii. 1997. Corpo e alma da magistratura brasileira. Rio de Janeiro. Editora Revan. 


\title{
RESUMOS/ABSTRACTS
}

\section{O SENTIDO DA JUDICIALIZAÇÃO DA POLÍTICA: DUAS ANÁLISES}

\author{
DÉBORA ALVES MACIEL \\ ANDREI KOERNER
}

Analisa-se o enfoque que vê as relações entre as instituições jurídicas e as instituições políticas sob o prisma da "judicialização". Dois livros recém-publicados nessa área (Ministério Público e política no Brasil, de Rogério Bastos Arantes, e A democracia e os três poderes no Brasil, organizado por Luiz Werneck Vianna) são examinados. tuições políticas.

Palavras-chave: Judicialização; instituições jurídicas; insti-

\section{THE MEANINGS OF “JURIDIFICATION"}

The approach which regards both juridical and political institutions through the prism of "juridification" is analyzed. The authors review two newly published books on the subject (Ministério Público no Brasil, by Rogério Bastos Arantes, and A democracia e os três poderes no Brasil, organized by Luiz. Werneck Vianna).

Keywords: Juridification; juridical institutions; political institutions. 